\title{
Em Busca de um Algoritmo de Retransmissão em Redes LoRaWAN
}

\author{
Thiago Vinney Oliveira Almeida ${ }^{1}$, João Pedro Pastório ${ }^{1}$ \\ Álvaro R. C. Souza ${ }^{1}$, Fabio A. Spanhol ${ }^{1}$, Edson T. de Camargo ${ }^{1}$ \\ ${ }^{1}$ Universidade Tecnológica Federal do Paraná (UTFPR) - Câmpus Toledo \\ Rua Cristo Rei, 19 - Vila Becker - CEP 85902-490 - Toledo - PR - Brasil
}

\begin{abstract}
Resumo. A rede de comunicação sem-fio e longa distância LoRaWAN vem sendo amplamente adotada para fornecer conectividade a objetos localizados tanto em centros urbanos quanto em localidades mais remotas. No entanto, o padrão LoRaWAN não apresenta uma estratégia para reenviar pacotes perdidos, apesar de apresentar marcações para solicitar a confirmação de um pacote recebido. Este trabalho propõe um algoritmo chamado CR-LoRaWAN para gerenciar a retransmissão de pacotes em redes LoRaWAN. Considerando um cenário de rastreamento de objetos em movimento, o algoritmo proposto foi avaliado em modelos de simulação bem como na implementação em um dispositivo de rastreamento. Os resultados apresentam a eficiência do algoritmo proposto ao compará-lo a uma estratégia onde não há confirmação.
\end{abstract}

\begin{abstract}
The LoRaWAN wireless and long-distance communication network has been widely adopted to provide connectivity to objects located both in urban centers and in more remote locations. However, the LoRaWAN standard does not present an algorithm to retransmit lost packets, despite having flags that allow an object to request the server to confirm the receipt of packets. This work proposes an algorithm named CR-LoRaWAN to manage packet retransmission in LoRaWAN networks. Considering a moving object tracking scenario, the proposed algorithm was evaluated in simulation models as well as implementation in a tracking device. The results show the efficiency of the proposed algorithm when comparing it to a strategy where there is no confirmation.
\end{abstract}

\section{Introdução}

O conceito de Internet das Coisas - ou IoT (Internet of Things) - define objetos conectados à Internet capazes de gerar informação e serem representados no mundo virtual [Bardyn et al. 2016]. A IoT compreende domínios de aplicação diversos, como cidades inteligentes [Centenaro et al. 2016] e agricultura [Tzounis et al. 2017]. Nesses domínios, aplicações vêm sendo desenvolvidas, por exemplo, para monitorar a umidade do solo em cultura agrícola [Rajkumar et al. 2017], coletar parâmetros de qualidade do ar em um centro urbano [Johnston et al. 2019] ou rastrear objetos em movimento em tempo real pela Internet [da Silva et al. 2020]. Tais aplicações compartilham entre si a dependência de uma rede de comunicação para enviar e receber dados.

Uma característica das redes de comunicação IoT é sua topologia dinâmica e instabilidade devido ao enfraquecimento de bateria, mobilidade, ruído, ou mesmo falha temporária no módulo de comunicação [Pastório et al. 2020]. O desafio é ainda maior devido 
aos enlaces sem-fio de curto e/ou longo alcance empregados na comunicação. Algumas aplicações aceitam a perda de alguns pacotes durante um intervalo de tempo, de modo que não é necessário implementar qualquer garantia de entrega. Por outro lado, certas aplicações não toleram perdas. Por exemplo, um dispositivo final IoT que tem como objetivo detectar a concentração de gases tóxicos em um ambiente requer que os dados enviados sejam de fato recebidos pelo servidor. Da mesma forma, ao rastrear um objeto em movimento, deseja-se conhecer todo o seu percurso ainda que em determinados trechos as coordenadas geográficas não sejam recebidas devido a obstáculos. Nesse sentido, apesar de instabilidades temporárias na comunicação, uma estratégia para assegurar que os dados foram de fato recebidos é essencial para o sucesso da aplicação.

No âmbito das redes de longo alcance e baixa potência, ou Low Power Wide Area Network (LPWAN) [Centenaro et al. 2016, Guibene et al. 2017], destaca-se o padrão aberto LoRaWAN. Construído com base na tecnologia sem fio Long Range (LoRa), o padrão caracteriza-se por cobrir extensas áreas (até 50 quilômetros), oferecer uma taxa de transferência baixa e não demandar pagamento de taxas de uso. O protocolo do padrão LoRaWAN oferece um mecanismo de confirmação por meio de algumas flags presentes no pacote. No entanto, tal protocolo não conta com um gerenciador que trate os pacotes não confirmados e agende os reenvios necessários, como acontece no Transmission Control Protocol (TCP) [Jacobson 1988]. Destaca-se que um pacote não confirmado pode ter sido realmente perdido, impactando também em como o dispositivo armazena temporariamente os pacotes até que haja sua confirmação.

O objetivo deste trabalho é propor um algoritmo eficiente para retransmitir pacotes em redes LoRaWAN. O algoritmo CR-LoRaWAN proposto é avaliado através de um estudo de caso usando o simulador de código aberto ns-3 [nsnam 2021]. O estudo de caso vem de uma parceria entre a Universidade e o Município que busca desenvolver uma solução de rastreamento em tempo real de caminhões da coleta seletiva de lixo usando uma rede LoRaWAN que está sendo implantada na área urbana do município. O objetivo da simulação é verificar a eficiência do algoritmo de confirmação em diferentes cenários de operação, ou seja, se o algoritmo proposto é capaz de reduzir a quantidade de pacotes perdidos. A solução também é programada e avaliada em um dispositivo chamado TTGO T-Beam. O T-Beam é um módulo microcontrolado construído em torno da estrutura do chip ESP32, incluindo um módulo GPS e transmissor LoRa.

Conforme observado em trabalhos anteriores [da Silva et al. 2020, Rossato et al. 2020, Ferreira et al. 2020], dispositivos empregados para rastrear objetos móveis geralmente perdem pacotes quando, por exemplo, o objeto passa por locais onde há obstáculos para propagação das ondas eletromagnéticas. Os resultados de simulação obtidos demonstram que o algoritmo CR-LoRaWAN é capaz de atenuar a perda de pacotes, aumentando em $15 \%$ a taxa de pacotes recebidos em um cenário com 3-5 gateways e alta obstrução. Já resultados obtidos do T-Beam mostraram que o algoritmo é capaz de retransmitir a maioria dos pacotes perdidos.

Este artigo está organizado da seguinte forma. A Seção 2 revisa brevemente os padrões LoRa e LoRaWAN. A Seção 3 descreve o algoritmo de retransmissão proposto e a metodologia de avaliação. A Seção 4 sumariza e discute os resultados obtidos. Finalmente a Seção 5 apresenta a conclusão e possíveis trabalhos futuros. 


\section{LoRa e LoRaWAN}

LoRa é uma tecnologia proprietária da Semtech. Seu objetivo é realizar comunicação de radiofrequência utilizando modulação derivada do espalhamento espectral por Chirp [Semtech Corporation 2015]. A tecnologia é basicamente uma implementação de camada física. Apesar disso, existem alguns pontos de camada de enlace definidos em LoRa, como formato de quadro e técnicas de código de erro. Por outro lado, LoRa não implementa o controle de acesso ao meio, tarefa fundamental de camada de enlace.

LoRaWAN é um protocolo de rede aberto, mantido pela LoRa Alliance, que tem como objetivo gerenciar uma LPWAN. LoRaWAN oferece segurança, comunicação bidirecional, mobilidade e localização dos serviços. Sua estrutura apresenta três tipos de dispositivos: dispositivos finais (end-devices), gateways e servidores de rede (network servers). Esses dispositivos são distribuídos em uma rede com topologia estrela de estrelas, em que os gateways conectam os dispositivos finais, no que seria uma topologia estrela, enquanto os gateways se conectam em topologia estrela aos servidores de rede, formando a estrela de estrelas. A rede opera com protocolo de múltiplo acesso baseado no protocolo ALOHA, em que um dispositivo, ao ter dados para transmitir, prepara o pacote e o envia, sem qualquer tipo de sondagem ao meio de transmissão [Beltramelli et al. 2020].

Os dispositivos finais se enquadram em três classes diferentes, sendo denominadas classe A, B e C. As classes se diferenciam no modo de envio e recepção, e apenas a classe A tem implementação obrigatória nos dispositivos. Essa classe é caracterizada por abrir duas janelas de recepção (downlink) logo após o uso de uma janela de transmissão (uplink), de modo que só pode receber dados após o envio de alguma informação. É considerada a classe mais econômica em termos energéticos, pois mantém o dispositivo final em repouso fora dos períodos de transmissão e recepção, i.e., no tempo ocioso [LoRa Alliance 2017]. Assim, é recomendada para dispositivos que precisam de pouca informação vinda da aplicação, e apenas após os processos de envio, o que pode ser visto como útil para dispositivos como sensores.

Redes LoRaWAN suportam a confirmação de mensagens, apesar de não possuírem um protocolo de controle de confirmação de mensagens, como Stop and Wait, Retransmissão Seletiva ou Go-Back-N. Para enviar mensagens que exigem o recebimento de confirmação, basta alterar o valor do campo MType do pacote. Esse campo, de 3 bits, é apresentado na Figura 1. Para enviar uma mensagem de uplink com confirmação, basta definir o MType com os bits 100 (ao invés de 010), enquanto que mensagens de downlink com confirmação usam o MType com os bits 101 (ao invés de 011).

\section{Materiais e Métodos}

Esta seção apresenta o algoritmo de controle de retransmissão CR-LoRaWAN proposto e os meios de obtenção de resultados. O sistema LoRaWAN permite, nativamente, o envio de mensagens com confirmação, porém não implementa uma solução de controle do processo de retransmissão. Para essa finalidade, o algoritmo CR-LoRaWAN (descrito na Seção 3.1) será empregado. Para obtenção de resultados, utiliza-se um dispositivo programado e também simulações via ns-3. A utilização de simulação é útil para verificar o impacto de diferentes variáveis, como as condições de propagação, número de gateways e quantidade de dispositivos finais operando. A investigação desses parâmetros seria mais difícil de se controlar (no caso das condições de propagação) e mais custosas (nos casos do 


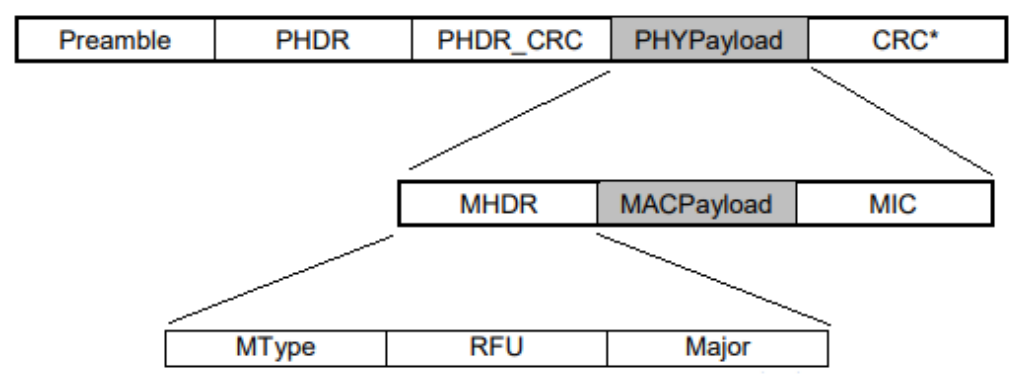

Figura 1. Localização do campo MType na estrutura de uma mensagem LoRa. Fonte: Adaptado de [LoRa Alliance 2017].

número de gateways e dispositivos ativos). Considerações sobre o dispositivo programado e o ambiente de simulação são feitas nas subseções 3.2 e 3.3, respectivamente.

Os parâmetros LoRa são os mesmos tanto para o dispositivo programado quanto para a simulação em ns-3. Utilizou-se o modelo AU915 de planejamento de canal, com canais de uplink de $125 \mathrm{kHz}$, modelo que é descrito para uso no Brasil pela ANATEL. O fator de espalhamento é configurado inicialmente para $S F=9$ e a taxa de codificação é dada por $C R=\frac{4}{5}$.

\subsection{Algoritmo de Controle de Retransmissão LoRaWAN}

O algoritmo CR-LoRaWAN é proposto para operação em dispositivos classe A, e tem como objetivo a entrega de pacotes transmitidos por esses dispositivos. Não se pode concluir, de antemão, que o algoritmo proposto é capaz de entregar todos os pacotes, mas espera-se que o mesmo seja capaz de garantir a entrega nos casos em que a comunicação não sofra com uma falha muito longa, dado que o dispositivo possui buffer limitado, pode operar também por tempo limitado e não está previsto que o mesmo mantenha os pacotes salvos para tentar retransmitir na próxima janela de utilização.

A implementação do algoritmo foi separada em dois planos: no plano de controle e gerenciamento, utilizou-se a linguagem $\mathrm{C}$, combinada com a biblioteca LMIC para o gerenciamento de acesso à rede LoRaWAN. No plano de armazenamento (buffer de armazenamento de pacotes), utilizou-se a linguagem de programação $\mathrm{C}++$. A biblioteca LMIC possui papel fundamental no processo de controle, principalmente ao prover eventos de interesse. Dentre os eventos, destacam-se os eventos de confirmação de mensagem, EV_TXCOMP LETE, e de ingresso na rede LoRaWAN, EV_JOINED.

O fluxograma do algoritmo CR-LoRaWAN é apresentado na Figura 2, sendo dividido em duas funcionalidades principais, mostradas na figura como \#1 e \#2. A função \#1 é responsável por retransmitir pacotes que não foram confirmados anteriormente, sendo ativada quando uma mensagem de confirmação de algum pacote é recebida. Adota-se esse comportamento pois o recebimento de uma confirmação indica que o dispositivo, naquele momento, está em uma área coberta por algum gateway, sendo um momento oportuno para transmitir algum pacote que tenha falhado anteriormente. Deste modo, ao receber uma confirmação, o dispositivo verifica se há pacotes que não receberam confirmação, e em caso positivo, começa a retransmiti-los. Se não houver pacotes nessa situação, ou todos já tiverem sido retransmitidos, retorna-se à função \#2. 


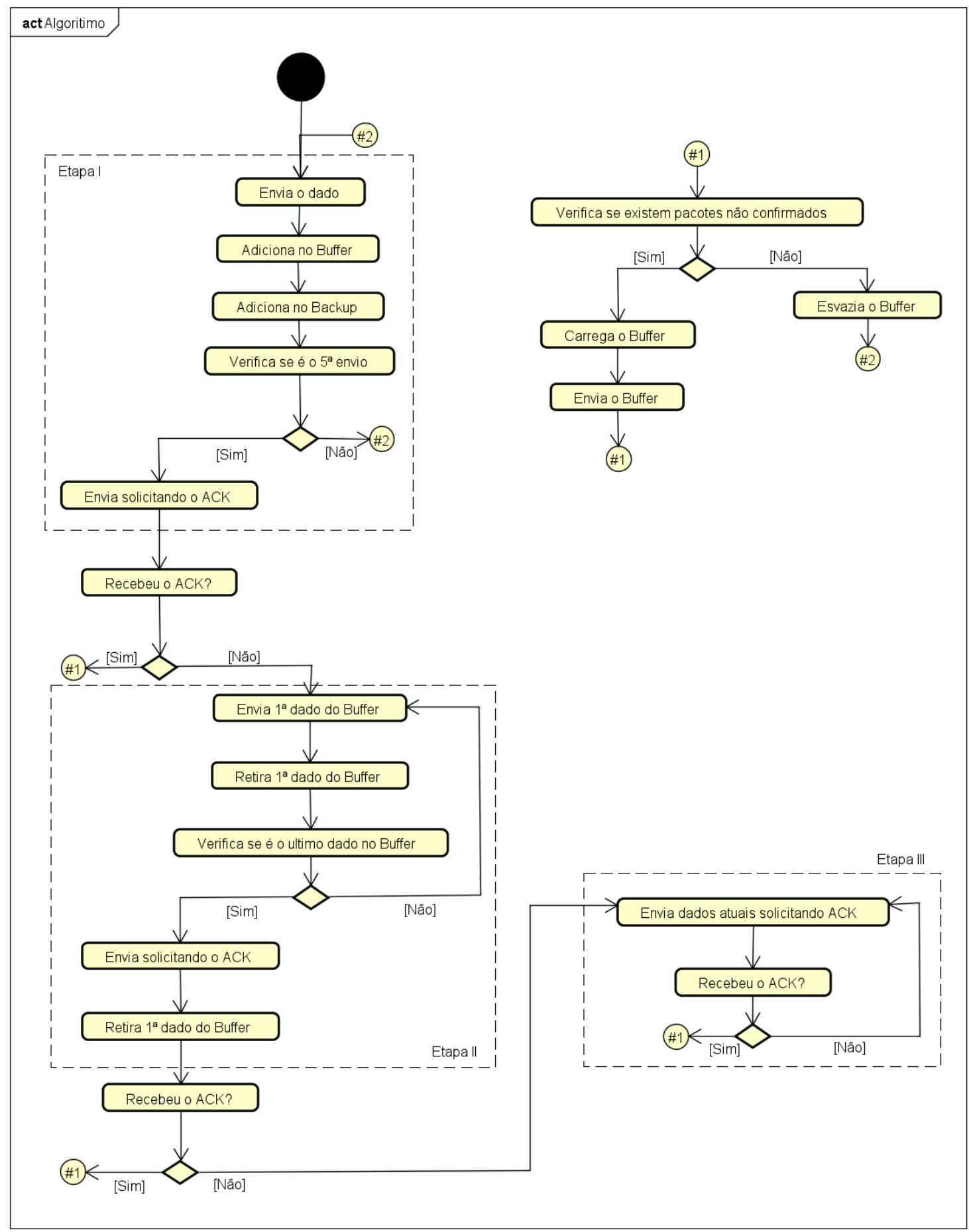

Figura 2. Fluxograma do algoritmo CR-LoRaWAN proposto.

A função \#2 é responsável pelo controle do processo de transmissão e confirmação, e para facilitar a explicação é subdividida em três etapas (de I a III), indicadas por retângulos tracejados na Figura 2. A Etapa I é responsável pela primeira tentativa de envio de um grupo de mensagens. São enviadas quatro mensagens sem confirmação, e a quinta mensagem fecha o grupo, sendo enviada com pedido de confirmação. Para enviar mensagens sem confirmação, configura-se o campo MType com o valor 010, que indica 
mensagens de uplink com confirmação desativada. Para as mensagens com confirmação, configura-se o MType com o valor 100, indicando mensagens de uplink com confirmação de recebimento. Caso a confirmação seja recebida nas janelas abertas pela operação em classe A, a função \#1 é executada, e posteriormente retorna-se à função \#1. No caso em que a confirmação não acontece, executa-se a Etapa II.

A Etapa II foi pensada para a possibilidade de que a interrupção de serviço seja curta, de modo que uma nova tentativa de envio do grupo deve ser suficiente para que os pacotes sejam confirmados. O processo de envio é similar ao da Etapa I, e no caso de se obter sucesso, o atraso desse grupo de pacotes é reduzido em comparação a colocá-los no fim da fila de transmissão. No caso de recebimento de confirmação, a função \#2 é executada; caso contrário, executa-se a Etapa III.

Finalmente, a Etapa III pode ser vista como a percepção de que o problema de conexão se mostra mais longo que o esperado, e não se sabe quando a comunicação será retomada. Assim, todos os pacotes enviados a partir desse ponto estão com pedido de confirmação ativado (MType em 100). Assim que um deles é confirmado, alterna-se para a função \#1 e, posteriormente, para a execução da função \#2.

A ideia de se agrupar as mensagens em blocos de 5 se dá por uma solução de compromisso. A confirmação de cada uma das mensagens demandaria uma grande quantidade de mensagens enviadas pelo gateway e aumento de processamento e gasto energético por conta dos dispositivos finais. Grupos muito grande de mensagens demandam o armazenamento de muitas mensagens e também podem gerar a retransmissão de muitas mensagens, dado que a falta da confirmação do grupo implica na retransmissão de todas as mensagens.

\subsection{Dispositivo Físico}

O dispositivo físico selecionado para o experimento foi o TTGO T-Beam, já avaliado no contexto do problema de rastreamento de veículos em um trabalho anterior [da Silva et al. 2020] tendo apresentado os melhores resultados em termos de cobertura. O T-Beam é composto por uma placa montada em torno de um chip ESP32 dual core em conjunto a um módulo LoRa, Semtech SX1276, e um módulo GPS, Ublox NEO-6M. A programação do dispositivo utilizou a biblioteca LMIC, modificada pela MCCI Corporation. A LMIC implementa uma abstração de hardware e é responsável pelos processos de gerenciamento de transmissão e comunicação no dispositivo final. Para programar o módulo GPS utilizou-se a biblioteca TinyGPS++.

Esse dispositivo será utilizado em um experimento de viabilidade da solução proposta, em testes controlados. Em um segundo momento, se faz necessário investigar o impacto de outros parâmetros de sistema, como por exemplo os cenários de propagação e o impacto da quantidade e localização dos gateways. Para prover maior flexibilidade nessas análises, será empregada também a simulação computacional, descrita a seguir.

\subsection{Simulação}

Foram realizadas simulações considerando dispositivos executando o algoritmo CRLoRaWAN em diversos cenários de operação para avaliar o impacto do algoritmo na redução de pacotes perdidos. Para modelar os cenários de simulação foi utilizado o simulador de código aberto ns-3 [nsnam 2021], versão 3.31. O ns-3 fornece mecanismos 
para simulação de redes em ambiente controlado utilizando um sistema de módulos independentes, que podem ser combinados para representar uma rede complexa. Um dos módulos utilizados foi o LoRaWAN [Magrin 2016], que fornece uma série de estruturas para reproduzir cada componente de uma rede LoRa.

Para a simulação do canal de transmissão foi utilizado o modelo de propagação de perda de percurso por distância logarítmica [Rappaport 2009]. A perda de percurso nesse modelo, em decibéis (dB), é mostrada na Equação 1:

$$
L=L_{0}+10 \times n \times \log _{10}\left(\frac{d}{d_{0}}\right),
$$

onde as distâncias estão em metros, sendo $d$ a distância entre transmissor e receptor; $d_{0}$ uma distância de referência tomada próxima ao receptor; $L_{0}$ a perda de percurso na distância de referência $d_{0}$ e $n$ o expoente de perda de percurso, podendo assumir valores distintos dependendo do ambiente a ser simulado [Rappaport 2009] com $n=2$ para modelo de campo aberto e $4 \leq n \leq 6$ para cenários densamente edificados.

Para simular os demais efeitos que impactam na atenuação de sinal, o módulo LoRaWAN implementa o modelo TR 45.820 para perdas ocasionadas por construções ou obstruções e uma correlação para sombreamento [Magrin 2016]. Para analisar os vários cenários de operação de uma rede LoRaWAN foram realizadas simulações com diferentes configurações, variando a quantidade e posicionamento de dispositivos finais e gateways presentes na rede. Também foram considerados diferentes ambientes de propagação do sinal, baseados no nível de obstrução do local em que os dispositivos estão inseridos, utilizando o módulo buildings do ns-3 para criar os três cenários seguintes:

- 0 - espaço sem obstáculos, simulando ambiente sem construções ou sombreamento, com $n=3,5$;

- 1 - ambiente pouco urbanizado, contando poucas obstruções prediais introduzidos com o módulo buildings, $\operatorname{com} n=3,75$;

- 2 - ambiente densamente construído, com grande quantidade de obstruções introduzidas pelo módulo buildings, comum a cenários urbanos, com $n=4$.

\section{Resultados e Discussão}

Esta seção apresenta o resultados obtidos por meio do dispositivo físico e simulação. A simulação primeiramente relata resultados variando o número de gateways e na sequência descreve a comparação do algoritmo com o um cenário onde não há retransmissão.

\subsection{Dispositivo Físico}

Os testes com o dispositivo T-Beam em ambiente controlado foram executados no campus Toledo da UTFPR com o dispositivo localizado a poucos metros do gateway, de modo que a conexão fosse a mais estável possível. Para se conseguir a perda de sinal em tal cenário foi utilizada uma caixa completamente revestida de papel alumínio, baseando-se no princípio de uma gaiola de Faraday. Optou-se por esse modelo de testes para controlar o momento e a duração do evento de interrupção do sinal. Após o T-Beam conectar-se na rede, o dispositivo realiza envios de alguns pacotes sem interferência até o sinal estar estabilizado. Em seguida o dispositivo é mantido em uma gaiola de Faraday por alguns 
minutos para que ocorra o bloqueio do sinal. Ao término desse período de interrupção o dispositivo é retirado da gaiola e mantido ligado até o algoritmo CR-LoRaWAN percorrer o atraso gerado durante o tempo sem sinal, ou seja, até que consiga retransmitir os pacotes sem confirmação e aqueles gerados posteriormente.

Foram realizados dois testes segundo essa abordagem: no Teste \#1 o dispositivo é mantido na gaiola por cerca de 1 minuto, enquanto que no Teste \#2 o tempo é incrementado para cerca de 2 minutos. Os resultados são apresentados na Tabela 1. A coluna "Quantidade de Pacotes impactados" corresponde à quantidade de pacotes que foram impactados pela interrupção de sinal, seja por aguardarem para retransmissão ou aguardarem que outros sejam retransmitidos para, então, serem transmitidos. Já a coluna "Quantidade de Pacotes confirmados" corresponde ao total de pacotes confirmados até o momento em que o teste é finalizado, o que é feito com o desligamento manual do dispositivo.

\begin{tabular}{ccccccc}
\hline & \multicolumn{2}{c}{ Intervalo (minutos) } & & \multicolumn{3}{c}{ Quantidade de Pacotes } \\
\cline { 2 - 3 } \cline { 5 - 7 } & perda sinal & teste & & gerados & confirmados & impactados \\
\cline { 2 - 3 } \cline { 5 - 7 } Teste \#1 & $01: 05$ & $05: 21$ & & 34 & 30 & 20 \\
& $01: 21$ & $05: 25$ & & 35 & 30 & 17 \\
& $01: 32$ & $05: 36$ & & 38 & 35 & 18 \\
\hline \multirow{3}{*}{ Teste \#2 } & $02: 09$ & $06: 32$ & & 41 & 40 & 26 \\
& $02: 23$ & $06: 22$ & & 42 & 40 & 26 \\
& $02: 12$ & $08: 03$ & & 50 & 45 & 29 \\
\hline
\end{tabular}

Tabela 1. Resultados dos testes com o dispositivo T-Beam.

Os resultados indicam uma taxa de tráfego confirmado, i.e., a razão entre a quantidade de pacotes confirmados e a quantidade pacotes gerados, de $89 \%$ no Teste \#1 e $94 \%$ no Teste \#2. Os testes não atingiram a totalidade de confirmações por conta da natureza de confirmação do algoritmo proposto: como o algoritmo confirma a cada 5 transmissões, a não ser que o total de pacotes seja múltiplo de 5 haverá pacotes não confirmados. Para resolver essa questão, pode ser necessário o envio de um pacote especial para indicar o fim de transmissão. No último caso do Teste \#2, uma hipótese para os últimos 5 pacotes não terem sido confirmados, é que o quinquagésimo pacote foi enviado logo após o dispositivo ter sido desligado. Como há um atraso para enviar um pacote de confirmação, é possível o dispositivo não estava ativo quando a confirmação foi enviada.

\subsection{Simulações}

\subsubsection{Modelo base}

Antes da avaliar o algoritmo CR-LoRaWAN foi realizada uma simulação base com o intuito de verificar o impacto da quantidade de gateways nos 3 diferentes cenários de obstrução de sinal descritos na Seção 3.3. Neste primeiro cenário, exibido na Figura 3, simulou-se o deslocamento do dispositivo final e registrou-se o percentual de pacotes recebidos nos gateways. O posicionamento dos gateways obedece ao projeto em andamento para implantação da rede LoRaWAN na cidade de Toledo [Rossato et al. 2020] e atualmente apenas o Gateway 1 da Figura 3 encontra-se instalado e operando. Os gateways são adicionados conforme a ordem de numeração, e cada ponto apresentado na Figura 4 foi simulado 100 vezes. 


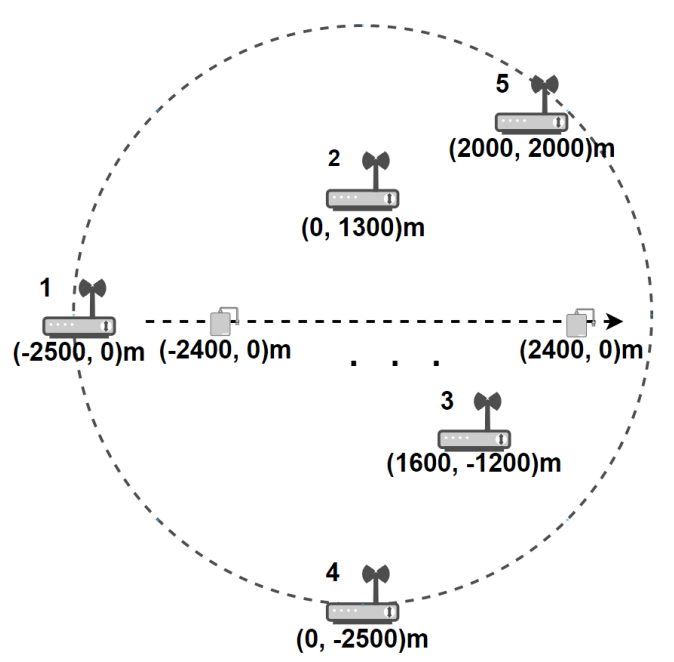

Figura 3. Representação do primeiro cenário simulado.

No cenário 0 (baixa obstrução do sinal), assim como esperado, o percentual de pacotes recebidos diminui conforme o dispositivo final afasta-se do gateway 1 chegando a apenas 20-30\%. Também como esperado, a adição de mais gateways (2-5) melhora essa situação. O comportamento da taxa de pacotes entregues em função da distância do dispositivo final e da quantidade de gateways pode ser observado na Figura 4.

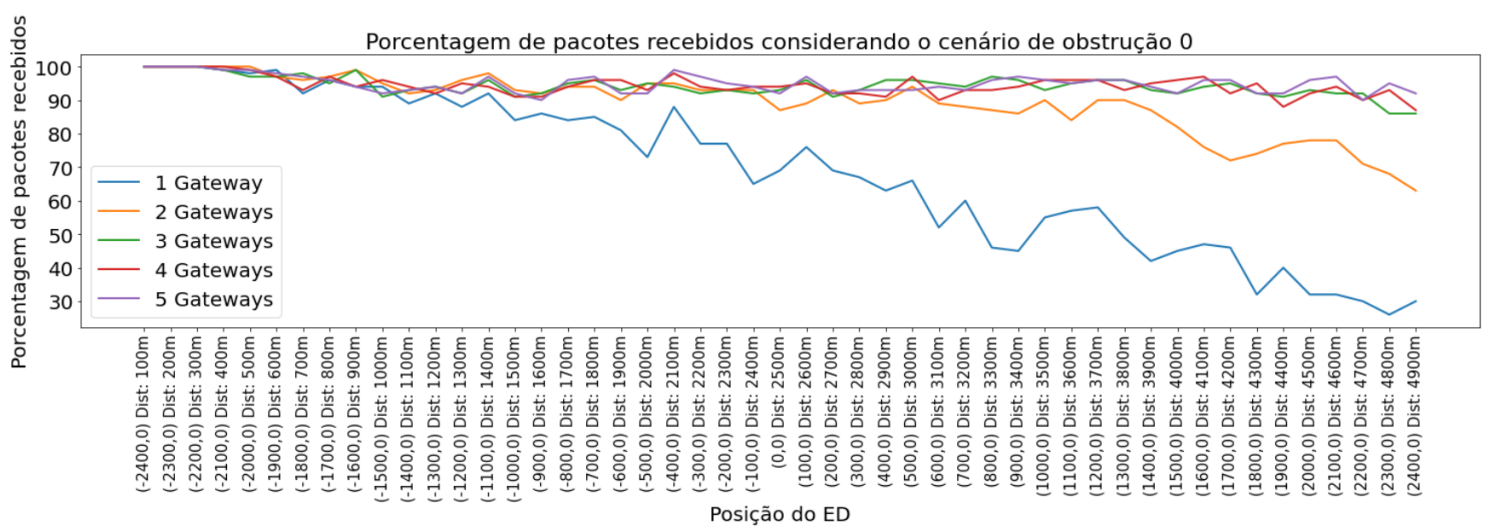

Figura 4. Resultado obtido com a primeira simulação no cenário 0 .

Com a introdução de obstruções no meio de propagação nos cenários 1 e 2 , simulando ambientes urbanos, nota-se uma acentuação na perda de pacotes. Mesmo a adição dos gateways 2-5 não garante um percentual satisfatório de entrega de pacotes. No cenário 2 (muitas obstruções e sombreamento, típico dos centros urbanos) para o final do percurso nos gateways 3-5 a taxa fica limitada a 50-60\%. Esse comportamento é mostrado na Figura 5.

Através dessas simulações percebemos que apesar da adição gateways incrementar o percentual de pacotes recebidos, em cenários com muitas obstruções, a perda de pacotes persiste. Logo, a utilização de um algoritmo de retransmissão torna-se essencial para tentar reduzir essa perda. 


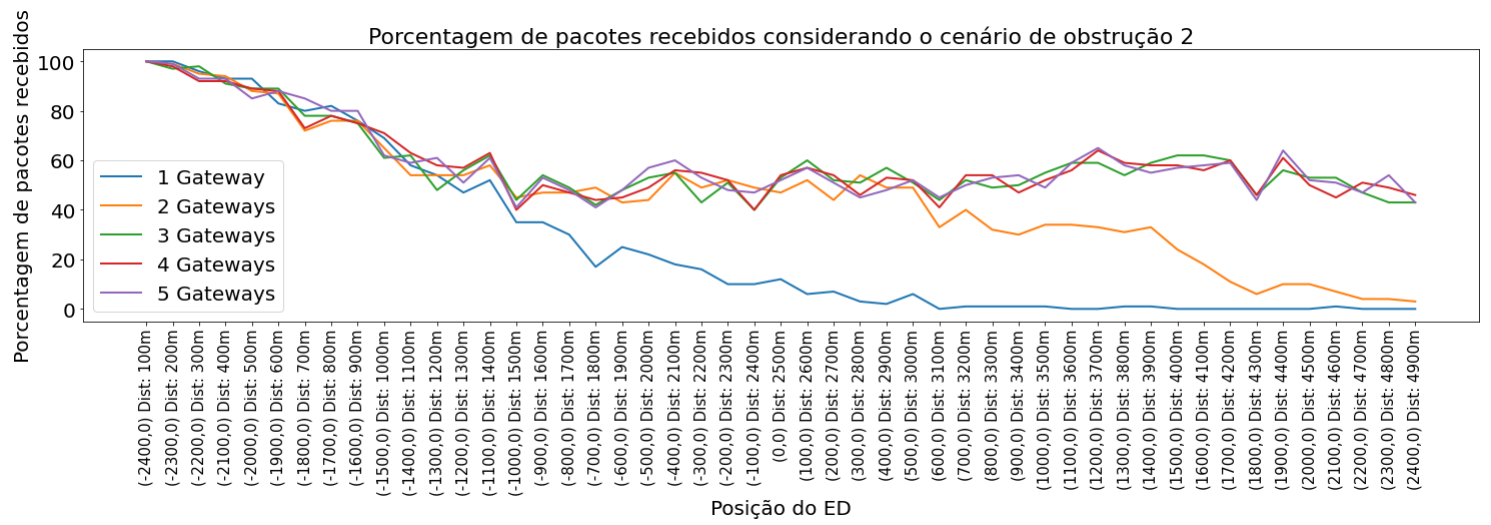

Figura 5. Resultado obtido com a primeira simulação no cenário 2.

\subsubsection{Modelo sem Retransmissão $x$ Modelo usando o algoritmo CR-LoRaWAN}

Partindo do modelo base foi introduzido o algoritmo CR-LoRaWAN já testado no dispositivo físico, com resultados apresentados na Seção 4.1. Nas simulações foi avaliado o impacto do algoritmo em dois aspectos: (a) tempo de entrega dos pacotes e (b) taxa de entrega dos pacotes.

Para o primeiro aspecto foi coletado o tempo de chegada do pacote no gateway e o tempo decorrido da geração do pacote no dispositivo final o seu recebimento em um gateway. Foram considerados três gateways em operação e o dispositivo final se deslocando conforme ilustra a Figura 6. Foi analisado o comportamento do algoritmo CR-LoRaWAN perante os três diferentes cenários de obstrução. Os resultados podem ser visto nas Figuras 7, 8 e 9, respectivamente.

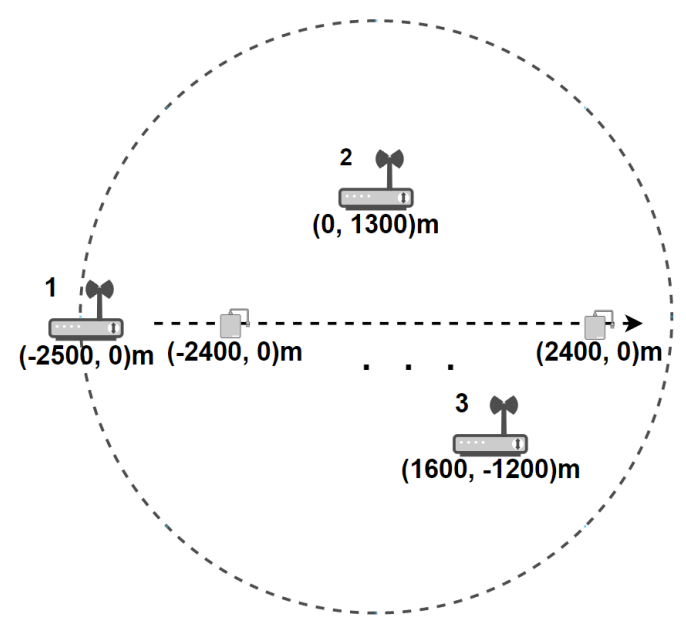

Figura 6. Modelo para avaliar o tempo de entrega de pacotes com CR-LoRaWAN.

Considerando inicialmente a Figura 7, apenas um pacote de dados não chegou a ser recebido na primeira transmissão, enquanto todos os outros foram recebidos sem a necessidade de retransmissão. Isso pode ser explicado pelo fato do cenário 0 simular um meio de propagação em ambiente aberto, sem obstruções ou sombreamento. Apesar de ideal é um modelo bastante distante do que ocorre em operações reais. 

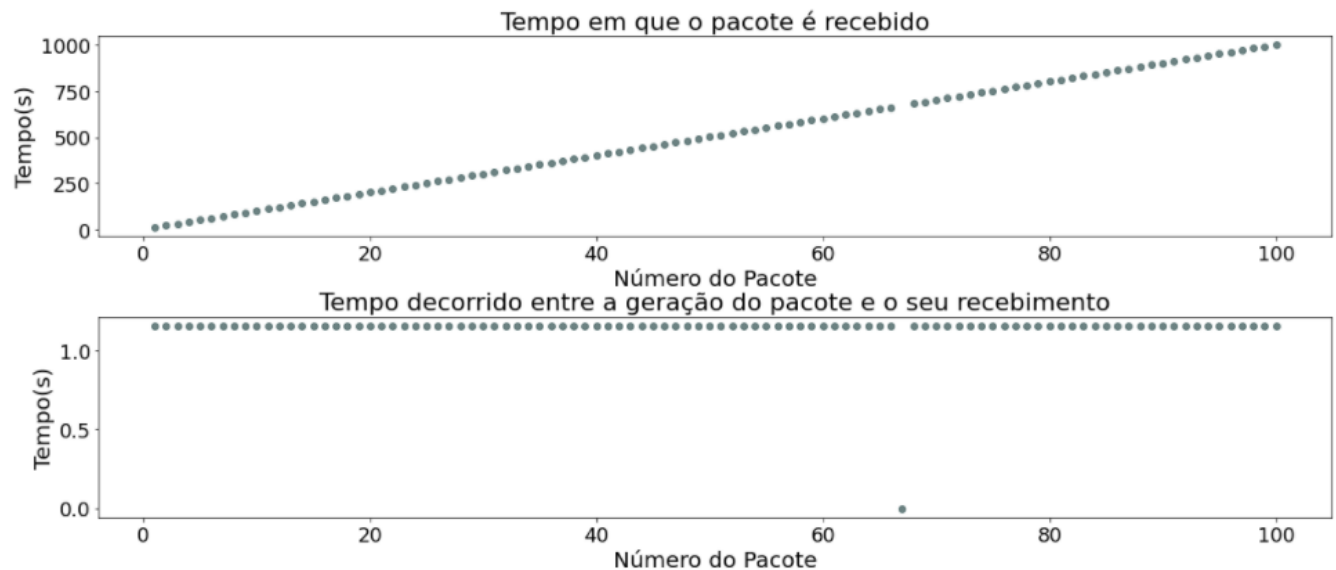

Figura 7. Algoritmo CR-LoRaWAN no cenário 0.
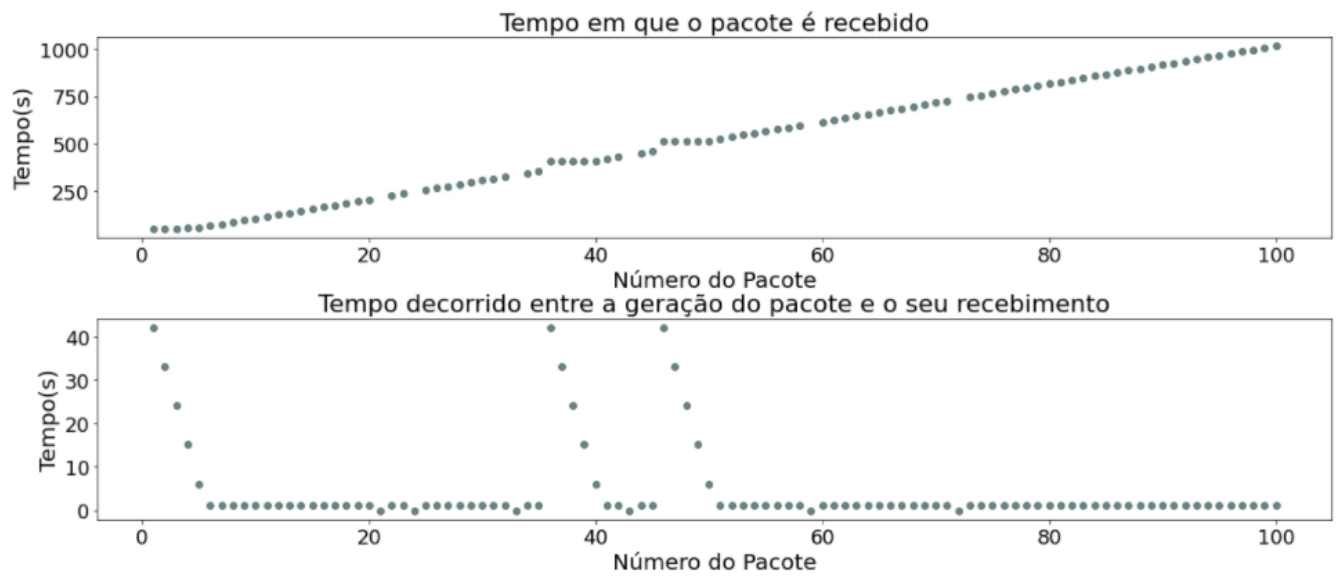

Figura 8. Algoritmo CR-LoRaWAN no cenário 1.
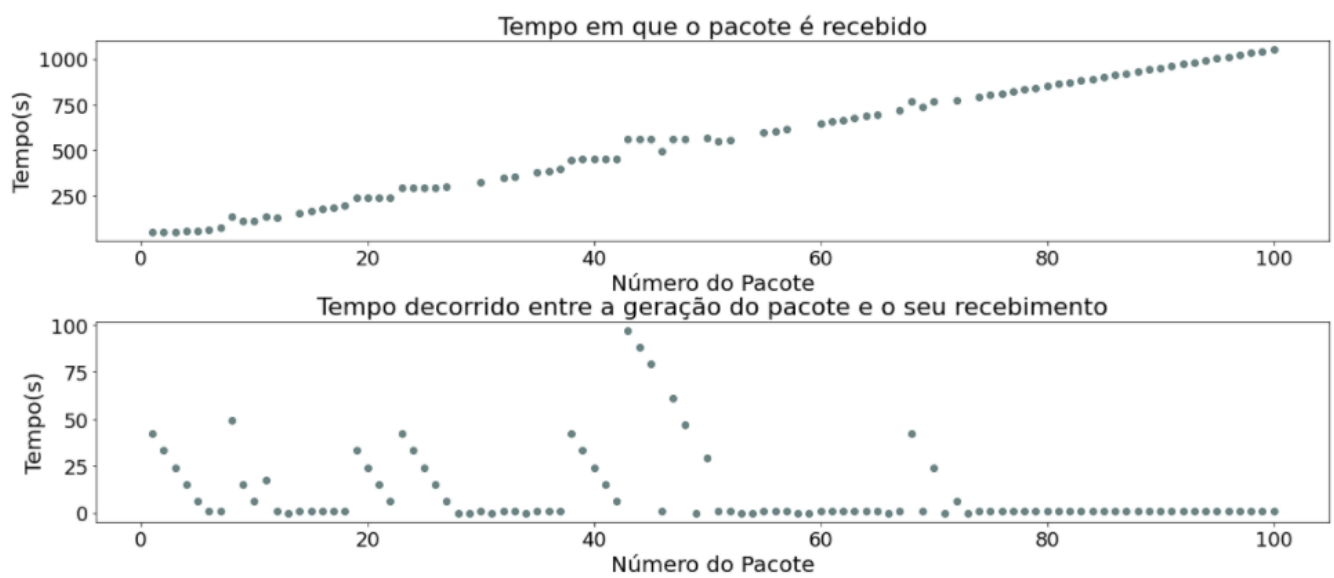

Figura 9. Algoritmo CR-LoRaWAN no cenário 2.

Na sequência, o nível de obstruções e sombreamento é aumentado, tornando o modelo simulado mais verossímil com áreas urbanas reais. Isso gera um aumento no número de pacotes não recebidos e consequentemente de retransmissões realizadas, como constata-se nas Figuras 8 e 9. Para o cenário 1, dos 100 pacotes enviados 6 não foram recebidos e 15 pacotes foram recebidos a partir de retransmissões. Esse valor sofre um 
aumento no cenário 2, saltando para 13 e 32, respectivamente. Assim, conclui-se que com o aumento no nível de obstruções presentes no ambiente há uma redução no número de pacotes recebidos, fazendo com que um algoritmo de retransmissão seja relevante.

$\mathrm{Na}$ taxa de recebimento de pacotes comparou-se o desempenho de um dispositivo final móvel com e sem a utilização do algoritmo CR-LoRaWAN. Para tanto considerou-se diferentes números de gateways ativos, variando de 1 a 5, adicionados de acordo com a ordem indicada na Figura 10. O dispositivo realiza um mesmo percurso repetidas vezes, gerando 1000 pacotes. Tal percurso consiste em uma trajetória de $3 \mathrm{~km}$ para norte, $3 \mathrm{~km}$ para leste, $3 \mathrm{~km}$ para sul e $3 \mathrm{~km}$ para oeste, visando alterar a distância entre o dispositivo final e os 5 gateways presentes na rede. A análise expandiu-se para os 3 diferentes níveis de obstrução, que foram colocados em paralelo na Figura 11. Ao analisar a Figura 11 se percebe que, independente do cenário de obstrução e da quantidade de gateways, o algoritmo CR-LoRaWAN aumenta o percentual de pacotes recebidos.

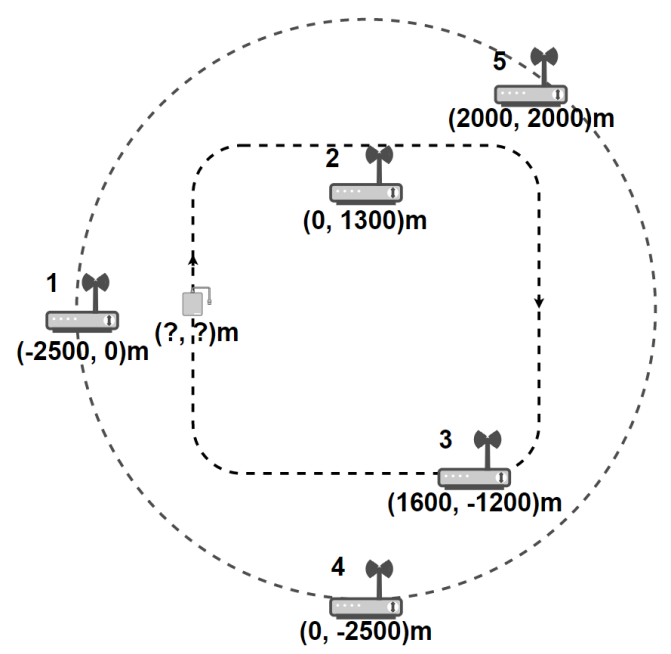

Figura 10. Modelo para avaliar a taxa de pacotes recebidos.

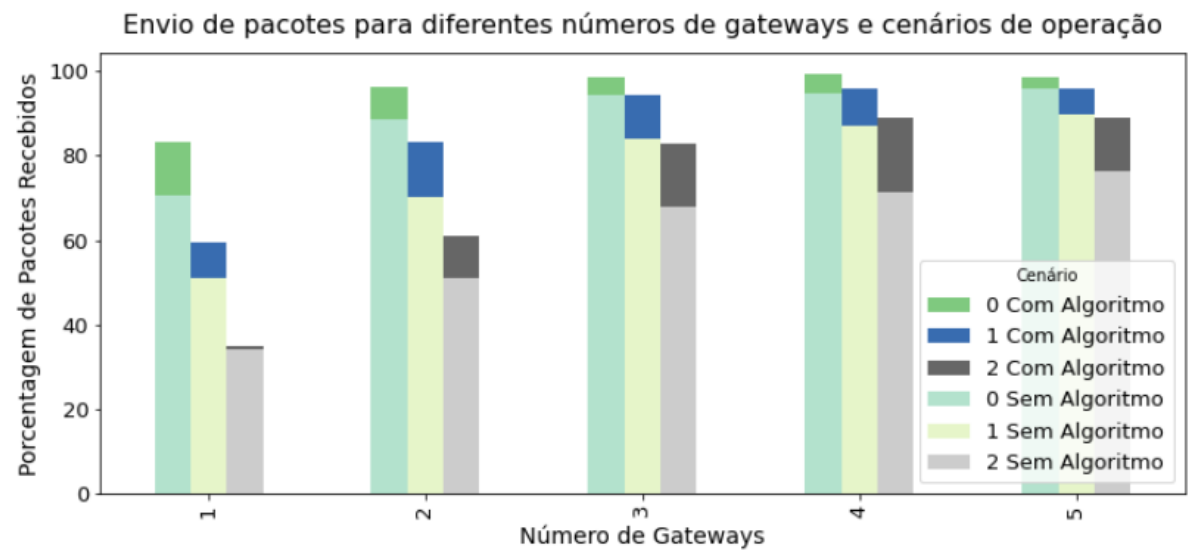

Figura 11. Comparativo entre uso ou não do algoritmo CR-LoRaWAN em diversos cenários de obstrução.

Para o cenário 0 , considerando apenas um gateway, o aumento do percentual de pacotes recebidos foi de $12,6 \%$, variando de $70,7 \%$ sem o algoritmo para $83,3 \%$ com o algoritmo CR-LoRaWAN. Nesse mesmo cenário, para dois gateways o aumento foi 
de 7,8\%, indo de $88,4 \%$ para $96,2 \%$. Já para 3-5 gateways esse aumento permaneceu próximo de $4 \%$ passando de $95 \%$ para $99 \%$. No cenário 1 , com um gateway foi observado um acréscimo de $9 \%$ no percentual de pacotes recebidos, indo de 50,6\% para $59,6 \%$, com dois gateways esse incremento foi de $13,2 \%$, indo de $70 \%$ para $83,2 \%$, enquanto que para 3-5 gateways houve um aumento de aproximadamente $10 \%$, variando de aproximadamente $85 \%$ para $95 \%$. Contudo, no cenário 2 de alta obstrução, com apenas um gateway, o ganho no percentual de pacotes recebidos foi menor do que nos demais cenários: aproximadamente $0,6 \%$. Para dois gateways houve um aumento de 10,3\%, de $50,8 \%$ para $61,1 \%$. Finalmente, para 3-5 gateways houve um aumento mais significativo, de aproximadamente $15 \%$, variando de $70 \%$ para $85 \%$.

\section{Considerações Finais}

Este trabalho apresentou o algoritmo CR-LoRaWAN para gerenciar a retransmissão de pacotes em redes LoRaWAN. O algoritmo proposto foi avaliado através do simulador de código aberto ns-3 e de um dispositivo programável micro-controlado chamado T-Beam que conta com sensor GPS e transmissor LoRa embutidos. Nos resultados com o TBeam, o CR-LoRaWAN foi capaz de confirmar $89 \%$ e $94 \%$ do tráfego gerado para os experimentos Teste \#1 e Teste \#2, respectivamente. Já os resultados de simulação mostram que mesmo ao adicionar mais gateways em cenários de maior obstrução, ainda há perda considerável de pacotes. Nesse aspecto, percebeu-se que conforme aumenta o nível de obstruções no ambiente há uma redução no número de pacotes recebidos, mostrando a importância do algoritmo CR-LoRaWAN. Em cenários para 3-5 gateways com alta taxa de obstrução houve um aumento de aproximadamente $15 \%$ na taxa de pacotes recebidos ao utilizar o algoritmo.

Em relação a trabalhos futuros, podem ser destacadas tanto análises mais detalhadas no CR-LoRaWAN quanto otimizações operacionais no próprio algoritmo, incluindo comparação com outras estratégias clássicas. Em relação às avaliações, é possível analisar o algoritmo quando existem mais dispositivos utilizando a rede LoRaWAN, o que pode impactar tanto na taxa de perda de pacote quanto na viabilidade da solução, a depender da ocupação da rede com retransmissões. As retransmissões impactam também no ciclo de trabalho (duty cycle) dos dispositivos que é regulamentado em alguns países. Também é necessário analisar soluções para os casos em que o último pacote do grupo é confirmado, porém alguns outros pacotes do mesmo grupo não são, o que pode levar a alterações no modelo do algoritmo. Ainda é possível a comparação com estratégias consagradas em redes de computadores, como Stop and Wait, Go-Back-N e Retransmissão Seletiva. Por fim, uma análise de interesse pode ser vista no consumo energético da solução e quantidade de mensagens, para averiguar sua viabilidade em dispositivos finais com restrição energética e também caracterizar a eficiência energética do algoritmo.

\section{Referências}

Bardyn, J., Melly, T., Seller, O., and Sornin, N. (2016). Iot: The era of lpwan is starting now. In ESSCIRC, pages 25-30.

Beltramelli, L., Mahmood, A., Osterberg, P., and Gidlund, M. (2020). LoRa beyond ALOHA: An investigation of alternative random access protocols. IEEE Transactions on Industrial Informatics, pages 1-1. 
Centenaro, M., Vangelista, L., Zanella, A., and Zorzi, M. (2016). Long-range communications in unlicensed bands: the rising stars in the iot and smart city scenarios. IEEE Wireless Communications, 23(5):60-67.

da Silva, M., de Souza, J., Almeida, T., Álvaro Souza, Spanhol, F., and Camargo, E. (2020). Avaliação de dispositivos de rastreamento em uma rede lorawan no contexto de cidades inteligentes. In Anais do IV Workshop de Computação Urbana, pages 1-14, Porto Alegre, RS, Brasil. SBC.

Ferreira, A., Molano, F., Costa, L., Foubert, B., Amadou, I., and Mitton, N. (2020). A study of the lora signal propagation in forest, urban, and suburban environments. Annals of Telecommunications.

Guibene, W., Nowack, J., Chalikias, N., Fitzgibbon, K., Kelly, M., and Prendergast, D. (2017). Evaluation of lpwan technologies for smart cities: River monitoring use-case. In IEEE WCNCW, pages 1-5.

Jacobson, V. (1988). Congestion avoidance and control. In Symposium Proceedings on Communications Architectures and Protocols, SIGCOMM, pages 314-329, New York, NY, USA. ACM.

Johnston, S. J., Basford, P. J., Bulot, F. M. J., Apetroaie-Cristea, M., Easton, N. H. C., Davenport, C., Foster, G. L., Loxham, M., Morris, A. K. R., and Cox, S. J. (2019). City scale particulate matter monitoring using lorawan based air quality iot devices. Sensors, 19(1).

LoRa Alliance (2017). LoRaWANTM 1.1 specification. LoRa Alliance, Beaverton, Oregon, Estados Unidos.

Magrin, D. (2016). Network level performances of a lora system. Master's thesis, Università degli Studi di Padova, Pádua. Orientador: Lorenzo Vangelista.

nsnam (2021). ns3: Network Simulator. nsnam.

Pastório, A., Rodrigues, L., and de Camargo, E. (2020). Uma revisão sistemática da literatura sobre tolerância a falhas em internet das coisas. In Anais Estendidos do X Simpósio Brasileiro de Engenharia de Sistemas Computacionais, pages 57-64, Porto Alegre, RS, Brasil. SBC.

Rajkumar, M. N., Abinaya, S., and Kumar, V. V. (2017). Intelligent irrigation system - an iot based approach. In 2017 International Conference on Innovations in Green Energy and Healthcare Technologies (IGEHT), pages 1-5.

Rappaport, T. S. (2009). Comunicações sem fio, Princípios e Práticas. Person Prentice Hall, São Paulo, SP.

Rossato, J., Spanhol, F., and Camargo, E. (2020). Implantação e avaliação de uma rede sem-fio de longo alcance e baixa potência para cidades inteligentes. In Anais do IV Workshop de Computação Urbana, pages 192-205, Porto Alegre, RS, Brasil. SBC.

Semtech Corporation (2015). AN1200.22 LoRa Modulation Basics. Semtech.

Tzounis, A., Katsoulas, N., Bartzanas, T., and Kittas, C. (2017). Internet of things in agriculture, recent advances and future challenges. Biosystems Engineering, 164:31 48. 